https://www.journal-imab-bg.org

Original article

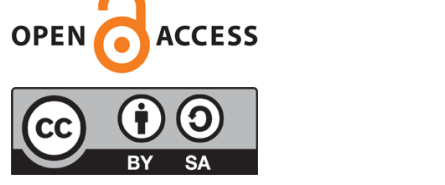

\title{
LOSS OF ARID 1A PROTEIN EXPRESSION IN OVARIAN ENDOMETRIOMAS AS A PROBABLE PREDISPOSITION TO DEVELOPMENT OF ENDOMETRIOSIS-ASSOCIATED OVARIAN CARCINOMAS
}

\author{
Tihomir Totev ${ }^{1}$, Grigor Gorchev ${ }^{2}$, Slavcho Tomov ${ }^{2}$ \\ 1) Institute of Science and Research, Medical University - Pleven, Bulgaria \\ 2) Oncogynaecology Clinic, University Hospital, Medical University - Pleven, \\ Bulgaria.
}

\begin{abstract}
Purpose: The aim of the study was to establish a loss of ARID 1A protein expression in cases of ovarian endometriomas and its probable role in the development of clear-cell and endometrioid ovarian carcinomas.

Material and Methods: The immunohistochemical analysis of ARID 1A protein expression was performed on specimens collected from the study group (group 1) that included 72 patients with endometrioid ovarian cysts. The control group (group 2) included 15 patients with clearcell and endometrioid ovarian carcinomas.

Results: In the study group, 1 of 72 specimens $(1,4 \%)$ showed a complete absence of reactivity and was defined as ARID 1A protein deficient. In the control group, 5 of 15 specimens $(33.3 \%)$ were found to be ARID 1A protein deficient. In $7(46.7 \%)$ cases of this group, together with the malignant component adjacent endometriosis was diagnosed. Two of these endometrioses were atypical, with an ARID 1A protein deficient expression.

Conclusions: These data confirm the hypothesis that in some endometriomas mutation of the tumor-suppressor ARID 1A gene occur, leading to the loss of protein expression and its functional activity, thus indicating a high risk for the development of endometriosis-associated ovarian cancer.
\end{abstract}

Key words: ARID 1A, endometrioma, endometriosis-associated ovarian carcinomas (EAOCs), ovarian clearcell carcinoma (OCCC), endometrioid ovarian carcinoma (EnOC)

\section{INTRODUCTION}

Endometriosis is an estrogen-dependent benign condition that affects $5-10 \%$ of females in reproductive age $[1,2]$. It is defined as the presence of endometrial glands and stroma outside the endometrial mucosa and uterine musculature [2]. In 1925 Sampson first described a malignant transformation of endometriosis into ovarian cancer. Since then, much evidence has been accumulated for the connection between endometriosis with two types of ovarian cancer: clear-cell and endometrioid [3, 4]. The transition from benign endometriosis to malignant neoplasms is a multifactorial and step-like process. One of the mechanisms of this transformation is related to the mutations of the tumor-suppressor gene AT rich interactive domain 1A (ARID 1A), which is located on the 1 ð36 chromosome. These mutations result in loss of synthesis of the protein BRG-associated factor 250a (BAF250a), which represents a large subunit of the transcription-regulating human SWI/SNF complexes and play an important role in the control of cell proliferation and tumor suppression [5, 6, 7]. Wiegand et al. [5] reported finding mutations of ARID 1A in $46 \%$ of 119 clear-cell ovarian carcinomas, in $30 \%$ of 33 endometrioid ovarian carcinomas, and none in 76 highly differentiated serous carcinomas. In some endometriomas, genetic and histological changes occur, which are an intermediate stage in the malignant transformation. The histological characteristics of these intermediate lesions, called "atypical endometriosis" were described by Czernobilsky and Morris [8], LaGrenade and Silverberg [9]. Areas with atypical endometriosis were identified in $54 \%$ of clear-cell and in $42 \%$ of endometrioid carcinomas [10]. Additional evidence regarding the importance of mutations of ARID 1A in the pathogenesis of EAOCs are cases, in which loss of protein BAF250a expression was seen as occurring simultaneously in observed ARID 1A mutation in a tumour and adjacent atypical endometriosis [5]. Samartzis et al. [11] found complete absence of BAF250a expression in 3 endometriomas $(n=3 /$ $20,15 \%), 1$ deep infiltrating endometriosis $(n=1 / 22,5 \%)$, while no such absence was established in peritoneal endometriosis $(n=0 / 16)$ and eutopic endometrium $(n=0 / 30)$. This was why we focused on the ovarian location of endometriosis as potential precancerosis. Since the immunohistochemistry of ARID 1A protein expression in EAOCs has demonstrated a high-degree correlation with gene mutations $[5,12]$, we used immunohistochemical analysis to detect probable molecular alterations in the lesions examined. The aim of our study was to investigate immunohistochemically the loss of ARID 1A protein 
expression in endometrioid ovarian cysts and its probable role in the development of endometriosis-associated ovarian carcinomas.

\section{MATERIALS AND METHODS}

\section{Patients and specimens}

The immunohistochemical analysis of ARID 1A protein expression was performed on specimens collected from the study group (group 1) that included benign endometriomas, and from the control group (group 2) consisting of clear-cell and endometrioid ovarian carcinomas. The study group included specimens from 72 patients with endometrioid ovarian cysts, operated on laparoscopically at the St Marina University Hospital Pleven during the period 2011-2014. The clinical endometriosis severity score was defined according to the revised American Society for Reproductive Medicine (rASRM) score (rASRM).

The control group included 15 patients, of whom 11 were operated on at St Marina University Hospital Pleven, and 4 were operated on at the Clinic of Oncogynaecology of the University Hospital in Pleven during the period 2012-2014. Of the cases from group 2, 8 were histologically diagnosed with clear-cell carcinoma and 7 - with endometrioid carcinoma. Ovarian carcinomas were staged using the International Federation of Gynecology and Obstetrics (FIGO) staging system, and the histological subtype and the degree of differentiation were defined according to the WHO classification.

Immunohistochemistry for ARID 1A Detection

The tissue samples were fixed in a $10 \%$ solution of formaldehyde and embedded in paraffin. Sections stained with hematoxylin/eosin were used for the routine histopathological investigation. We used a commercially available polyclonal rabbit anti-ARID1A antibody (HPA005456; Sigma-Aldrich;diluted 1:200) for ARID1A protein detection. Sections were deparaffinized and boiled in a microwave oven at $98^{\circ} \mathrm{C}, 800 \mathrm{~W}$ for $30 \mathrm{~min}$ in Dako En vision FLEX Target retrieval solution, low $\mathrm{pH}$ ( $0.01 \mathrm{~mol} / 1$ citrate buffer, $\mathrm{pH}$ 6.0citrate buffer, $\mathrm{pH}$ 6.0). The sections were then allowed to cool at room temperature. The activity of endogenic peroxidase was blocked using $3 \%$ hydrogen peroxide. The slides were then incubated at $22-24^{\circ} \mathrm{C}$ with the primary antibody for one hour and were then treated with a dextran polymer reagent, combined with secondary antibody and peroxidase (Dako En vision FLEX/HRP) for $30 \mathrm{~min}$ at room temperature. Specific antigen-antibody reactions were visualized using $0.2 \% 3,3^{\prime}$ diaminobenzidine tetrachloride in an organic solvent. Counterstaining was performed using Mayer's hematoxylin. Normal (non-neoplastic) endothelial cells, fibroblasts and lymphocytes show nuclear ARID 1A immunoreactivity and serve as a positive internal control [13]. Sections without primary antibody served as negative controls. All endometrioid cysts of the group 1 and EAOCs of group 2 were defined as ARID 1A intact (immunoreactive) or ARID 1A deficient (non-immunoreactive). The specimens with any level of immunoreactivity present were defined as ARID 1A intact. In EAOCs with adjacent endometriosis, immunoreactivity of the benign and malignant components was evaluated.

Statistical analysis

Descriptive method was made.

\section{RESULTS}

ARID 1A immunoreactivity in ovarian endometriomas

The tissue specimens in the study group were collected from endometrioid ovarian cysts measuring 1-12 $\mathrm{cm}$ in diameter. The mean diameter was $5.2 \mathrm{~cm}$. In this group were included only histologically benign ovarian endometriomas. There were no cases exhibiting the histological characteristics of "atypical endometriosis". 62 patients $(86.1 \%)$ had stage III (moderate) endometriosis, and $10(13.9 \%)$ had stage IV (severe) endometriosis. Of the 72 specimens, $71(98.6 \%)$ showed well-expressed diffuse immunoreactivity and were defined as ARID 1A protein intact. One sample $(1.4 \%)$ showed a complete absence of immunoreactivity and was defined as ARID 1A protein deficient (Table 1).

Table 1. Frequency distribution of results from investigating ARID A1 expression

\begin{tabular}{|l|c|c|c|c|c|c|}
\hline \multirow{2}{*}{ ARID 1A } & \multicolumn{3}{|c|}{ Study group } & \multicolumn{3}{c|}{ Control group } \\
\cline { 2 - 7 } & $\mathbf{N}$ & Relative share (\%) & Sp & N & Relative share (\%) & Sp \\
\hline Negative & 1 & 1.4 & 1.4 & 5 & 33.3 & 12.2 \\
\hline Positive & 71 & 98.6 & 1.4 & 10 & 66.7 & 12.2 \\
\hline All & 72 & 100.0 & & 15 & 100.0 & \\
\hline
\end{tabular}

ARID 1A immunoreactivity in endometriosis-associated ovarian carcinomas

The tissue specimens in the control group were collected from tumors sized 4 to $30 \mathrm{~cm}$ in diameter, mean size $11.3 \mathrm{~cm}$. In the EAOCs group, 8 patients were histologically diagnosed with clear-cell carcinoma, and 7 - with endomerioid carcinoma: stage I -9 patients $(60 \%)$, stage
II -3 patients $(20 \%)$, stage III -2 patients $(13.3 \%)$, and stage IV - 1 patient $(6.7 \%)$. In $7(46.7 \%)$ cases of this group, together with the malignant component, adjacent endometriosis was diagnosed. In the tumors with adjacent endometriosis, immunoreactivity of the benign and malignant components was evaluated (Table 2). 
Table 2. Frequency distribution of carcinomas combined with endometriosis (control group)

\begin{tabular}{|l|c|c|c|}
\hline Combined with endometriosis & N & Relative share (\%) & Sp \\
\hline None & 8 & 53.3 & 12.9 \\
\hline Benign ARID 1A + & 3 & 20.0 & 10.3 \\
\hline Benign ARID 1A - & 2 & 13.3 & 8.8 \\
\hline Atypical ARID 1A - & 2 & 13.3 & 8.8 \\
\hline All & 15 & 100.0 & \\
\hline
\end{tabular}

Of the 15 samples, $10(66.7 \%)$ showed different degrees of diffuse immunoreactivity and were defined as ARID $1 \mathrm{~A}$ protein intact. The total absence of reactivity was found in 5 specimens, and they were defined as ARID 1A protein-deficient. Of 7 endometrioid carcinomas, 2 were ARID $1 \mathrm{~A}$ protein-deficient and were combined with adjacent atypical endometriosis, also ARID 1A protein-deficient. The other 5 endometrioid carcinomas were found immunoreactive: in one case the carcinoma was combined with non-atypical endometriosis, also ARID 1A protein-intact, and in one case the carcinoma was combined with cystadenofibroma with borderline malignancy (Figure 1).

Fig. 1 (a, b, c, d) a. Endometrioid carcinoma (HE) b. EnOC-adjacent atypical endometriosis (HE) c. Endometrioid carcinoma (ARID A1 deficient) d. EnOC-adjacent atypical endometriosis (ARID A1 deficient)
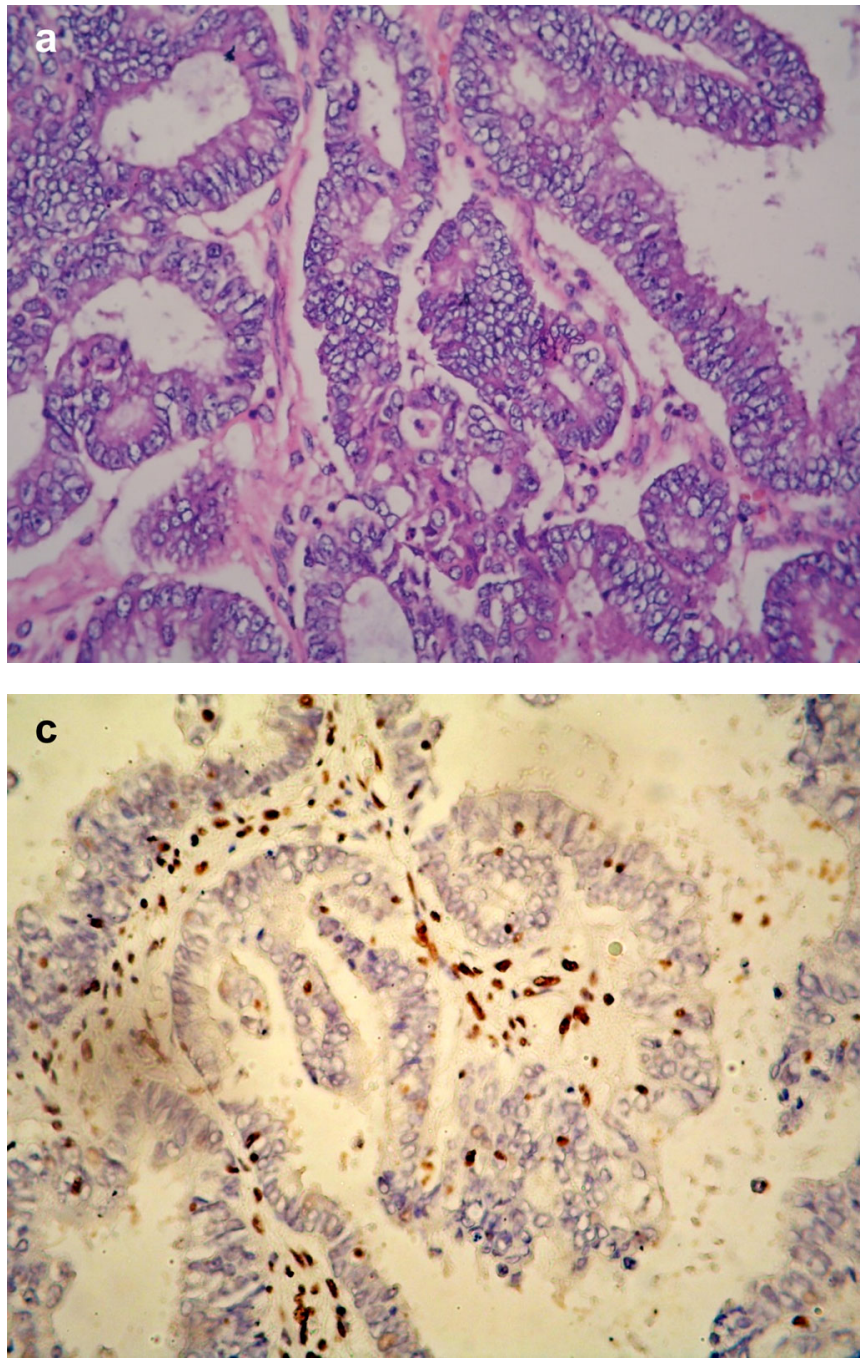

Three out of 8 clear-cell carcinomas were ARID 1A protein-deficient, and 2 of these 3 were associated with adjacent benign (non-atypical) endometriosis, also ARID 1A protein-deficient. The other 5 clear-cell carcinomas showed
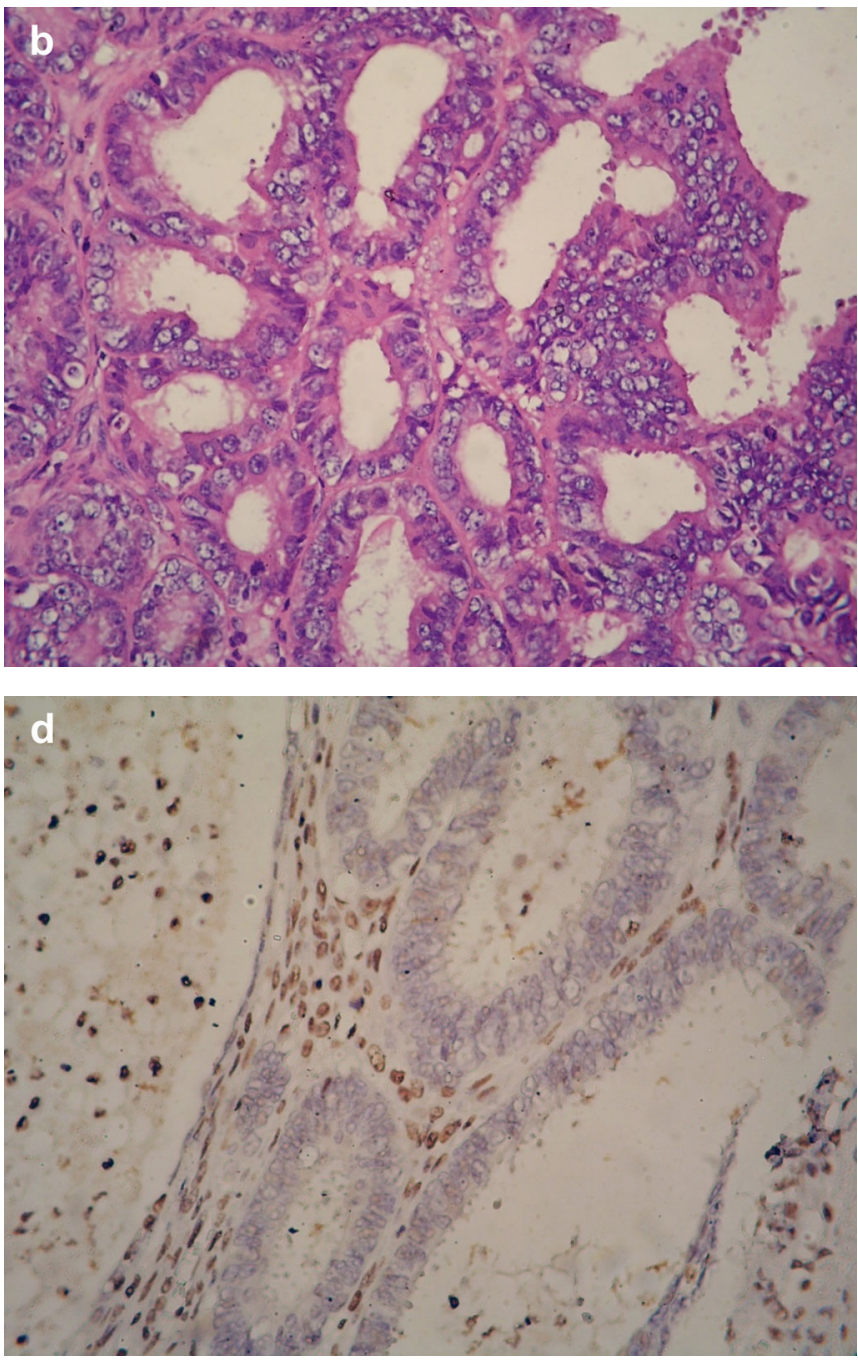

immunoreactivity, 2 being combined with non-atypical endometriosis. This component was also ARID 1A proteinintact (Figure 2). 
Fig. 2 (a, b, c, d) a. Clear-cell carcinoma (HE) b. OCCC-adjacent endometriosis (HE) c. Clear-cell carcinoma (ARID A1 focally deficient) d. OCCC-adjacent endometriosis (ARID A1 focally deficient)
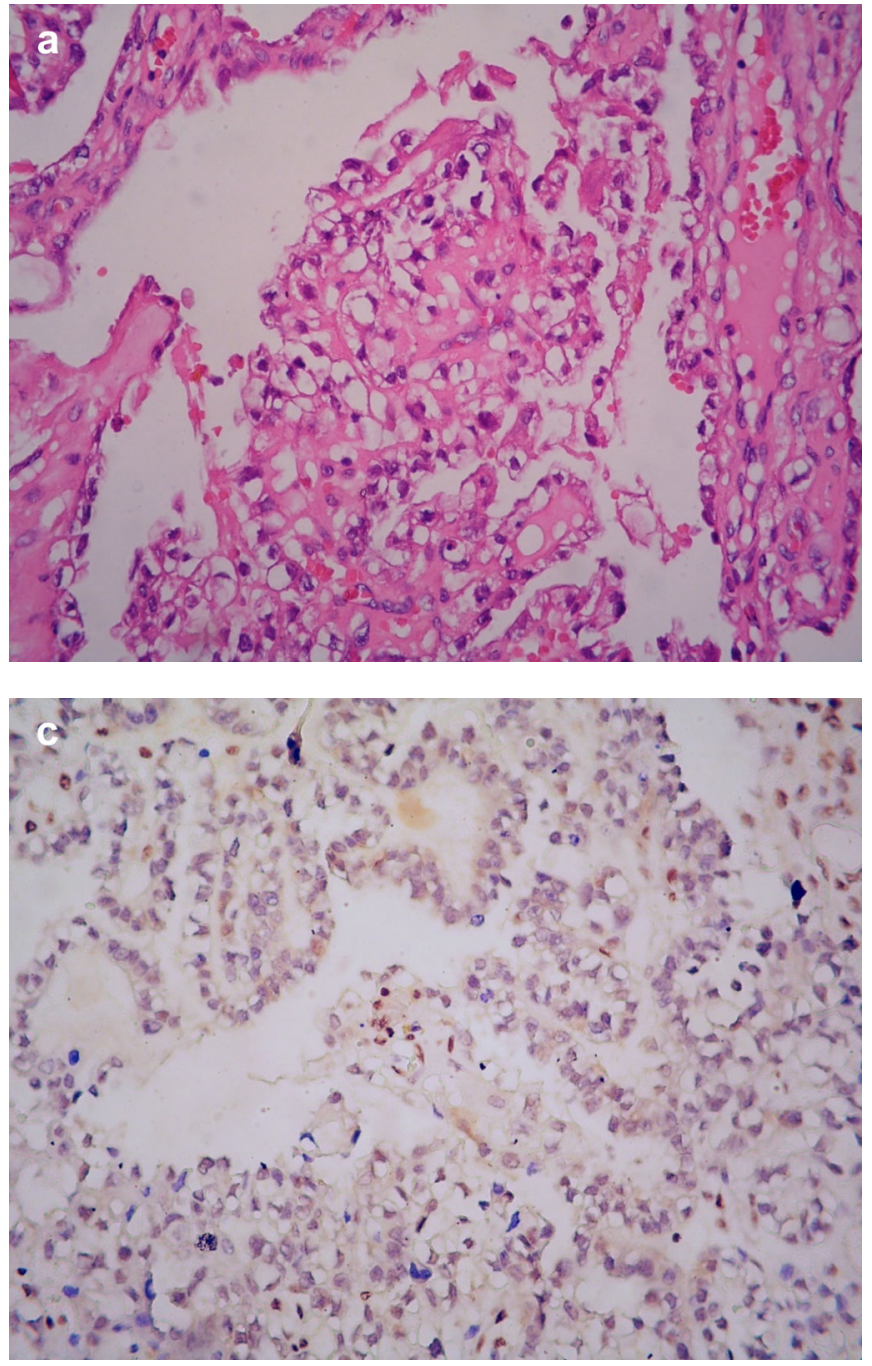

DISCUSSION

Ovarian endometriosis is a benign condition, and its transformation into certain subtypes of cancer is rare [6]. Many pathogenetic factors in an endometrioma are known that are likely to cause the first molecular alterations in DNA in a clone of cells which changes may trigger a malignant transformation. The most important of these are chronic inflammation and increased level of estrogen, oxidative stress resulting from the accumulation of heme and free iron. It is not known, however, which of the clinical features of the endometrioma (size, the continuance of the lesion, etc.) are associated with increased risk. Two studies have pointed to a statistically significant three-fold endometriosis [14, 15]. Brinton et al. have reported a risk for ovarian cancer that was 4.2 times higher in a cohort of 20686 females with ovarian endometriosis of long duration [16]. Clear-cell ovarian carcinomas account for $12 \%$, and endometrioid carcinomas - for $11 \%$ of epithelial malignant ovarian tumors [17]. Clear-cell ovarian carcinomas demonstrate a behaviour different from that of the most common serous tumors: they are comparatively more resistant to conventional chemotherapy with taxane and platinum-based cytostatic drugs and have a poorer prognosis
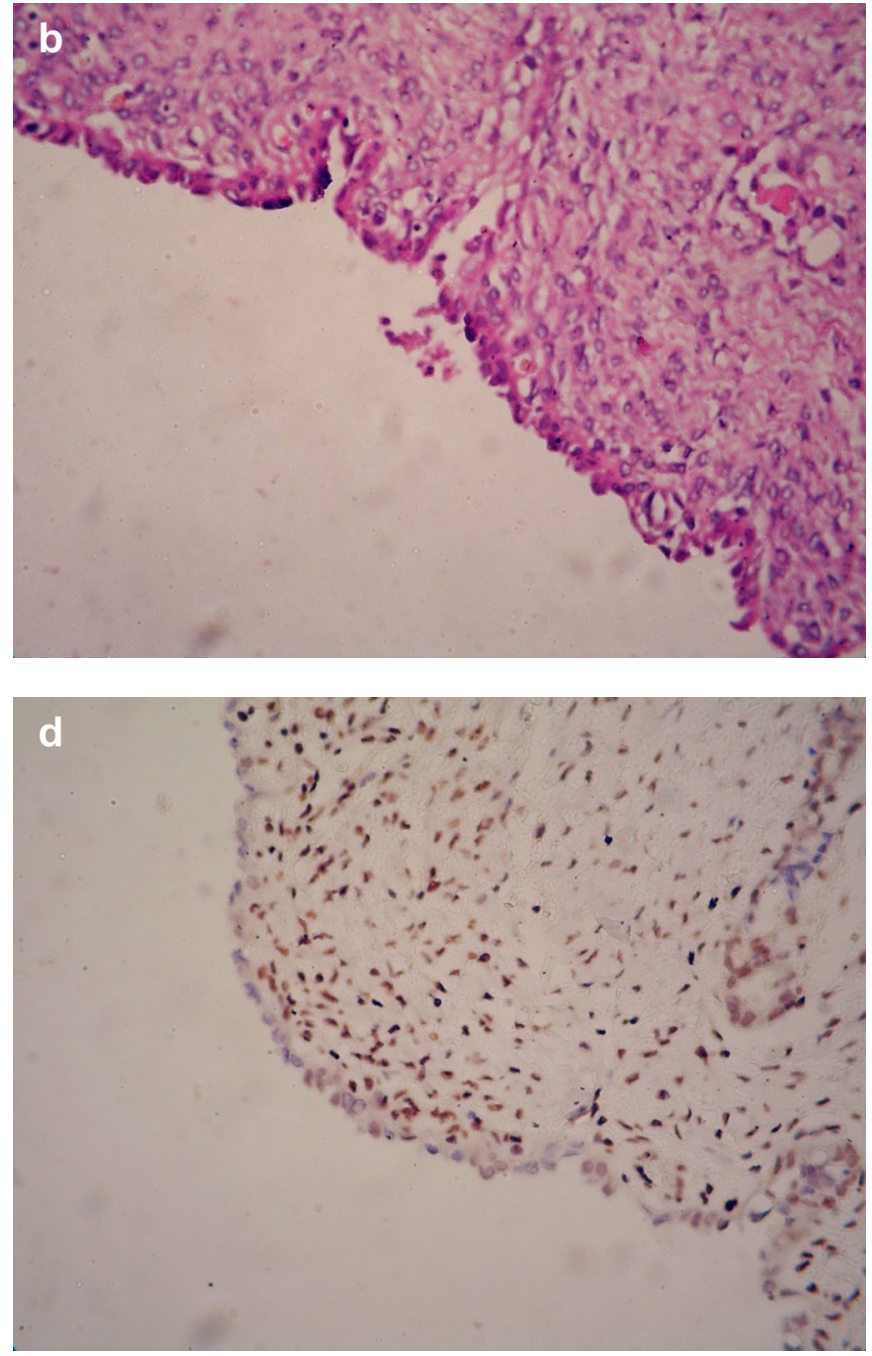

in advanced stages, especially in cases of insufficient surgical cytoreduction $[18,19,20]$. Since the role of endometrioid ovarian cysts as precursors of a significant number of EAOCs has been undoubtedly proven, a question arises in which of these cysts there exists a higher risk of malignant transformation. Mutations of the tumor-suppressor ARID 1À gene are among the commonest gene mutations that trigger carcinogenesis, and these mutations can be detected immunohistochemically through the expression of the protein encoded in this gene. Our study confirms the facts that have been reported so far: 1. Although rarely $(1.4 \%)$, this phenomenon occurs in some endometriomas, found to be completely histologically benign. This proves to be one of the earliest and highly important events in carcinogenesis. 2 . In the series we study here were two cases in group 2 featuring the histological structure of adjacent "atypical endometriosis", which has been identified as a missing link between benign endometriomas and EAOCs. They were, similarly to the adjacent malignant component, ARID 1A protein-deficient. 3. The occurrence of EAOCs in endometrioma was clearly demonstrated in group $2-47.6 \%$ of the cases, as was the complete loss of ARID 1A immunoreactivity in $33.3 \%$ of the cases. No statistically reliable 
analysis can be made because only one patient of the 72 in the group 1 was found with ARID A1 protein deficient expression, and 5 out of the 15 cases were ARID 1A protein deficient in the group 2.

\section{CONCLUSION}

The loss of the protein coded by ARID 1A that was proved immunohistochemically could be considered as a biomarker indicating an increased risk in cases of endometrioid ovarian cysts. The majority of the patients were young females with non-accomplished or partially accomplished reproductive functions, undergone organ-sav- ing surgery. The question whether the immunohistochemical investigation of ARID 1A protein expression can be effectively used in practice as a screening method in view of designing an individual approach in observation or further treatment is yet to be elucidated by more studies in multiple centers.

\section{Acknowledgements}

The study was supported by a grant from Medical University - Pleven, Bulgaria. It was approved by the Commission for Scientific Research Ethics of Medical University - Pleven.

\section{REFERENCES:}

1. Bulun SE. Endometriosis. $N$ Engl J Med. 2009 Jan 15;360(3):268-79. [PubMed] [Crossref]

2. Giudice LC, Kao LC. Endometriosis. Lancet. 2004 Nov 13-19; 364(9447):1789-99. [PubMed]

3. Ness RB. Endometriosis and ovarian cancer: thoughts on shared pathophysiology. Am J Obstet Gynecol. 2003 Jul;189(1):280-94. [PubMed]

4. Somigliana E, Vigano' P, Parazzini F, Stoppelli S, Giambattista E, Vercellini P. Association between endometriosis and cancer: a comprehensive review and a critical analysis of clinical and epidemiological evidence. Gynecol Oncol. 2006 May; 101(2):331-41. [PubMed]

5. Wiegand KC, Shah SP, Al-Agha OM, Zhao Y, Tse K, Zeng T, Senz J. et al. ARID1A mutations in endometriosis-associated ovarian carcinomas. $N$ Engl J Med. 2010 Oct 14;363(16): 1532-43. [PubMed] [Crossref]

6. Wang X, Nagl NG Jr, Flowers S, Zweitzig D, Dallas PB, Moran E. Expression of p270 (ARID1A), a component of human SWI/SNF complexes, in human tumors. Int J Cancer. 2004 Nov 20;112(4):636. [PubMed]

7. Reisman D, Glaros S, Thompson EA. The SWI/SNFcomplex and cancer. Oncogene. 2009 Apr 9;28(14):165368. [PubMed] [Crossref]

8. Czernobilsky B, Morris WJ. A histologic study of ovarian endometriosis with emphasis on hyperplastic and atypical changes. Obstet. Gynecol.

\section{Mar;53(3):318-23. [PubMed]}

9. LaGrenade A, Silverberg SG. Ovarian tumors associated with atypical endometriosis. Hum. Pathol. 1988 Sep;19(9):1080-84. [PubMed]

10. Fukunaga M, Nomura K, Ishikawa E, Ushigome S. Ovarian atypical endometriosis: its close association with malignant epithelial tumours. Histopathology. 1997 Mar; 30(3):249-55. [PubMed]

11. Samartzis EP, Samartzis N, Noske A, Fedier A, Caduff R, Dedes KJ, et al. Loss of ARID 1A/BAF250a-expression in endometriosis: a biomarker for risk of carcinogenic transformation? Mod. Patol. 2012 Jun;25(6):88592. [PubMed] [Crossref]

12. Maeda D, Mao TL, Fukayama M, Nakagawa S, Yano T, Taketani Y, et al. Clinicopathological significance of loss of ARID1A immunoreactivity in ovarian clear cell carcinoma. Int $\mathrm{J} \mathrm{Mol}$ Sci. 2010; 11(12):5120-28. [PubMed] [Crossref]

13. Yamamoto S, Tsuda H, Takano M, Tamai S, Matsubara O. Loss of ARID 1A protein expression occurs as an early event in ovarian clear-cell carcinoma development and frequently coexists with PIK3CA mutations. Mod Patol. 2012 Apr;25(4):615-24 [PubMed] [Crossref]

14. Rossing MA, Cushing-Haugen KL, Wicklund KG, Doherty JA, Weiss NS. Risk of epithelial ovarian cancer in relation to benign ovarian conditions and ovarian surgery. Cancer Causes Control. 2008 Dec;19(10):

\section{7-64. [PubMed] [Crossref]}

15. Worley MJ, Welch WR, Berkowitz RS, Ng SW. Endometriosisassociated ovarian cancer: a review of pathogenesis. Int J Mol Sci. $2013 \mathrm{Mar}$ 6;14(3):5367-79. [PubMed] [Crossref]

16. Brinton LA, Gridley G, Persson I, Baron J, Bergqvist A. Cancer risk after a hospital discharge diagnosis of endometriosis. Am J Obstet Gynecol. 1997 Mar;176(3):572-79. [PubMed]

17. Koebel M, Kalloger SE, Huntsman DG, Santos JL, Swenerton KD, Seidman JD. Differences in tumor type in low-stage versus high-stage ovarian carcinomas. Int J Gynecol Pathol. 2010 May;29(3):203-211. [PubMed] [Crossref]

18. Anglesio MS, Carey MS, Koebel M, Mackay H, Huntsman DG. Clear cell carcinoma of the ovary: a report from the first Ovarian Clear Cell Symposium, June 24th, 2010. Gynecol Oncol. 2011 May 1;121(2):407-15. [PubMed] [Crossref]

19. Itamochi H, Kigawa J, Terakawa N. Mechanisms of chemoresistance and poor prognosis in ovarian clear cell carcinoma. Cancer Sci 2008 Apr;99(4):653-58. [PubMed] [Crossref]

20. Sugiyama T, Kamura T, Kigawa J, Terakawa N, Kikuchi Y, Kita T. et al. Clinical characteristics of clear cell carcinoma of the ovary: a distinct histologic type with poor prognosis and resistance to platinum-based chemotherapy. Cancer. 2000 Jun 1;88(11): 2584-89. [PubMed] 
Please cite this article as: Totev T, Gorchev G, Tomov S. Loss of ARID 1A protein expression in ovarian endometriomas as a probable predisposition to development of endometriosis-associated ovarian carcinomas. J of IMAB. 2019 JulSep;25(3):2611-2616. DOI: https://doi.org/10.5272/jimab.2019253.2611

Received: 05/12/2018; Published online: 22/07/2019

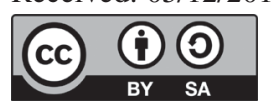

\section{Corresponding Author:}

Tihomir P. Totev MD, PhD

St. Marina University Hospital, Department of Gynecology

Bulgarska aviatsia str., Pleven 5800, Bulgaria. tel. +359 888848326

E-mail: t.totev@mail.bg 